\title{
AVALIAÇÃo dA FITODISPONIBILIDADE DE CÁDMIO, CHUMBO E CRÔMIO, EM SOJA CULTIVADA EM LATOSSOLO VERMELHO ESCURO TRATADO COM FERTILIZANTES COMERCIAIS
}

\author{
Affonso Celso Gonçalves Junior* \\ Departamento de Química - Universidade Federal de Santa Catarina - CP 476 - 88040-900 - Florianópolis - SC \\ Eduardo Bernardi Luchese \\ Departamento de Agronomia - Universidade Estadual do Oeste do Paraná - 85960-000 - Marechal Cândido Rondom - PR \\ Ervim Lenzi \\ Departamento de Química - Universidade Estadual de Maringá - 87020-900 - Maringá - PR
}

Recebido em 4/1/99; aceito em 29/9/99

\begin{abstract}
EVALUATION OF PHYTOAVAILABILITY OF THE CADMIUM, LEAD AND CHROMIUM IN SOYBEAN CULTIVATED IN THE LATOSSOLO VERMELHO ESCURO, TREATED WITH COMMERCIAL FERTILIZERS. The aim of this work was to evaluate the availability of the toxic heavy metals: cadmium, lead and chromium, in soybean, from some fertilizers. Five fertilizers and soluble salts contend $\mathrm{Cd}, \mathrm{Pb}$ and $\mathrm{Cr}$ were used. All the treatments were accomplished in vases of 2,5 $\mathrm{L}$ with application of two doses, 50 and $100 \mathrm{~kg} . \mathrm{ha}^{-1}$ for the fertilizers and 25 and $50 \mathrm{~kg} . \mathrm{ha}^{-1}$ for the salts.
\end{abstract}

Keywords: soybean; heavy metals; fertilizers.

\section{INTRODUÇÃO}

A deficiência de micronutrientes nos solos agrícolas representa uma preocupação crescente, com tendência a se acentuar num futuro próximo. O cultivo em solos de baixa fertilidade, a calagem e o aumento da produtividade, são fatores que têm favorecido o aumento das deficiências de micronutrientes ${ }^{1}$.

Comprovada a deficiência de micronutrientes, o agricultor procura suprir a falta destes elementos com a aplicação de fertilizantes específicos. Estes produtos são comercializados com grande diversidade de nutrientes, no mínimo dois, embora possam ser encontrados com teores de nutrientes bem elevados ${ }^{1}$.

Os fertilizantes utilizados para suprir micronutrientes possuem uma composição, que além dos elementos desejáveis, também, em geral, contém metais pesados tóxicos.

A expressão "metal pesado" se aplica a elementos que tem peso específico maior que $5 \mathrm{~g} . \mathrm{cm}^{-3}$ ou que possuem número atômico maior que $20^{2}$.

Metais pesados são importantes em diversos meios, alguns são usados industrialmente em países de tecnologia avançada. Muitos são fisiologicamente essenciais para plantas e animais, como o $\mathrm{Cu}$ (formação de melanina nas plantas e pigmentação da pele dos animais), o Zn (síntese do DNA e RNA em plantas e animais), e, deste modo, contribuem na saúde humana e na produtividade agrícola, porém, muitos destes metais pesados são poluentes de ecossistemas ${ }^{3}$.

$\mathrm{Na}$ lista dos metais pesados estão com maior frequência os seguintes elementos: $\mathrm{Cu}, \mathrm{Fe}, \mathrm{Mn}, \mathrm{Mo}, \mathrm{Zn}, \mathrm{Co}, \mathrm{Ni}, \mathrm{V}, \mathrm{Ag}, \mathrm{Cd}, \mathrm{Cr}$, $\mathrm{Hg}$ e $\mathrm{Pb}$. Entre os micronutrientes aparecem vários metais pesados classificados como: essenciais: $\mathrm{Cu}, \mathrm{Fe}, \mathrm{Mn}$, Mo e $\mathrm{Zn}$, são elementos benéficos e indispensáveis para o desenvolvimento das plantas; benéficos: $\mathrm{Co}, \mathrm{Ni}$ e $\mathrm{V}$, são elementos que colaboram com o desenvolvimento das plantas, mas sua falta não é considerada um fator limitante; não essenciais ou tóxicos: $\mathrm{Cd}, \mathrm{Cr}, \mathrm{Hg}, \mathrm{Pb}$, entre outros, sendo elementos prejudiciais às plantas ${ }^{3}$.

$\mathrm{O}$ aumento anormal das concentrações de metais pesados nos solos de agricultura altamente tecnificada é resultado da deposição atmosférica e da aplicação de agrotóxicos, resíduos orgânicos e inorgânicos urbanos industriais, fertilizantes e corretivos ${ }^{4-5-6}$.

A justificativa deste trabalho partiu de uma situação levantada no segundo semestre de 1989 , quando a imprensa divulgou a existência de exportações de lixo industrial, o qual continha metais pesados tóxicos, para países do terceiro mundo, dentre estes o Brasil. Durante as discussões ficou caracterizada a utilização de parte deste lixo na fabricação de fertilizantes destinados a suprir micronutrientes para as plantas ${ }^{1}$.

Retomou-se esta discussão quando o Greenpeace impediu a saída de navios de portos europeus, contendo as referidas cargas. Novamente, o Brasil encontrava-se entre os países que as receberiam.

Devido à falta de rigidez da legislação no que tange ao descarte indiscriminado de lixo industrial, muitos subprodutos são comercializados como fertilizantes contendo micronutrientes.

Alguns destes subprodutos podem também conter quantidades apreciáveis de metais pesados tóxicos, tais como: cádmio, crômio, níquel e chumbo. A disponibilidade de metais pesados para as plantas não tem sido claramente definida nos estudos até então realizados, mas seus efeitos devem ser mínimos em decorrência das pequenas doses aplicadas ${ }^{7}$.

Nem todos os órgãos das plantas possuem a mesma sensibilidade quanto à acumulação de metais pesados. Normalmente, a raíz é o órgão prioritário de entrada e acumulação dos metais pesados ${ }^{2}$.

A toxidez de um elemento deve ser acompanhada e por isso medida pelas seguintes variáveis: diminuição no crescimento ou redução na colheita, sintomas visíveis e concentração no tecido ${ }^{8}$.

Este trabalho objetivou avaliar a fitodisponibilidade dos metais pesados tóxicos cádmio, chumbo e crômio na cultura de soja (Glycine max (L) Merril), cultivada num latossolo vermelho escuro, com aplicações de alguns fertilizantes comerciais.

\section{MATERIAL E MÉTODOS}

\section{Coleta e Preparo dos Solos}

Retiraram-se amostras de solo da camada arável $(0-20 \mathrm{~cm})$ de um solo tipo latossolo vermelho escuro (LE). As amostras, protegidas de poeira, foram secadas ao ar, e, logo após, passadas em peneira de $4 \mathrm{~mm}$, forma em que foram levadas aos vasos e em peneira de $2 \mathrm{~mm}$ para análises laboratoriais. Coletou-se o solo na Fazenda Experimental da Universidade Estadual de Maringá, localizada no Distrito de Iguatemi, Maringá-PR. 


\section{Análises Preliminares}

\section{Análises químicas e físicas dos solos e fertilizantes}

Efetuaram-se análises químicas para fins de fertilidade e análises físicas para determinação granulométrica, no laboratório de análise de rotina do Departamento de Agronomia da Universidade Estadual de Maringá. Os resultados encontramse nas Tabelas 1 e 2, respectivamente.

Tabela 1. Caracterização química da fertilidade do solo.

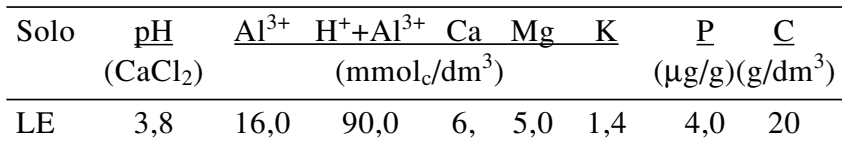

$\mathrm{pH}$ em $\mathrm{CaCl}_{2} 0,01 \mathrm{~mol} / \mathrm{L}$ : acidez ativa; $\mathrm{H}^{+}+\mathrm{Al}^{3+}$ : acidez potencial $\mathrm{Al}^{3+}$ : acidez trocável ${ }^{11}$.

Extrator de Fósforo (P) Mehlich ( $\mathrm{HCl} 0,05 \mathrm{~mol} / \mathrm{L}+\mathrm{H}_{2} \mathrm{SO}_{4}$ $0,025 \mathrm{~mol} / \mathrm{L})^{11}$.

$\mathrm{mmol}_{\mathrm{c}} / \mathrm{dm}^{3}$ : milimol de carga por decímetro cúbico de solo ${ }^{11}$.

Tabela 2. Análise física do solo para determinação granulométrica.

\begin{tabular}{|c|c|c|c|c|}
\hline Solo & $\frac{\text { Areia Grossa }}{(\%)}$ & $\frac{\text { Areia Fina }}{(\%)}$ & $\frac{\text { Silte }}{(\%)}$ & $\frac{\text { Argila }}{(\%)}$ \\
\hline LE & 28 & 38 & 2 & 32 \\
\hline
\end{tabular}

A análise dos fertilizantes e dos solos para determinação dos metais pesados tóxicos, cádmio $(\mathrm{Cd})$, chumbo $(\mathrm{Pb})$ e crômio $(\mathrm{Cr})$, foi realizada através de digestão nitro-perclórica e os metais determinados seguindo-se técnicas de Espectrometria de Absorção Atômica, modalidade chama ${ }^{9-10}$. Os resultados encontram-se nas Tabelas 3 e 4, respectivamente.

Tabela 3. Determinações de cádmio, chumbo e crômio nos fertilizantes.

\begin{tabular}{lccc}
\hline Fertilizante & cádmio & chumbo & crômio \\
\cline { 2 - 4 } & & $\left({\left.\mathrm{mg} \cdot \mathrm{kg}^{-1}\right)}\right.$ & \\
\hline Stimussed Plus & 4,0 & 1623 & 6500 \\
BR-12 Especial & 164 & 6132 & 104 \\
FTE-Cerrado & 323 & 1713 & 169 \\
Zincogran & 99 & 1464 & 1111 \\
Micronutri 121 & 10,8 & 1960 & 292 \\
\hline
\end{tabular}

Tabela 4. Determinações de cádmio, chumbo e crômio no solo LE.

\begin{tabular}{lccc}
\hline Solo & cádmio & chumbo & cromo \\
\cline { 2 - 4 } & & $\left({\left.\mathrm{mg} \cdot \mathrm{kg}^{-1}\right)}\right.$ & \\
\hline LE & $0,00^{*}$ & 1,75 & 2,50 \\
\hline
\end{tabular}

* Valor de concentração abaixo do limite de detecção do método.

\section{Determinação da capacidade máxima de retenção de água dos solos}

Em recipientes descartáveis de $50 \mathrm{~mL}$, previamente pesados, possuindo na base pequenos orifícios, colocaram-se $30 \mathrm{~g}$ de solo, em triplicata. O sistema assim preparado foi levado a uma bandeja contendo uma lâmina de água de $10 \mathrm{~mm}$, para saturação da amostra por capilaridade, durante 24 horas. Após, removeram-se os recipientes colocando-os sobre papel absorvente por 12 horas, para retirar o excesso de água, para posterior pesagem. A diferença entre o solo seco e úmido foi dada em porcentagem e considerada como capacidade de retenção de água dos mesmos ${ }^{12}$.

\section{Instalação e Condução do Experimento em Casa de Vegetação}

\section{Preparação dos vasos}

Foram utilizados vasos de PVC de 2,5 litros de capacidade, revestidos internamente com sacos de polietileno, evitando-se assim, o contato dos solos com as paredes dos vasos.

\section{Calagem}

Para determinar a necessidade de calagem, foram feitas curvas de calibração, incubando-se as amostras de solos em copos plásticos de $300 \mathrm{~mL}$ juntamente com doses de $\mathrm{CaCO}_{3}$ p.a. equivalentes a 2, 4, 6, 8 t.ha ${ }^{-1}$, com três repetições por tratamento. As amostras foram mantidas com $70 \%$ da capacidade de retenção de água, através da pesagem e correção da umidade duas vezes ao dia. Os vasos foram cobertos com uma lâmina de polietileno para evitar evaporação excessiva. $\mathrm{O}$ pH do sistema foi determinado aos doze e quinze dias após a instalação do experimento, fazendo-se coleta de uma amostra de cada copo. Os resultados mostraram que quinze dias foram suficientes para a completa reação do $\mathrm{CaCO}_{3}$ nos solos. Os resultados da incubação encontram-se na Tabela 5 .

Tabela 5. Efeito da incubação na alteração do pH dos solos, após 15 dias de incubação.

\begin{tabular}{lccccc}
\hline Solo & \multicolumn{6}{c}{ Quantidade } & $\mathrm{CaCO}_{3} \mathrm{em} \mathrm{t}^{-\mathrm{ha}^{-1}}$ & \\
\cline { 2 - 6 } & 0 & 2 & 4 & 6 & 8 \\
$\mathrm{LE}$ & 4,6 & 5,7 & $\frac{\mathrm{pH}}{6,0}$ & 6,3 & 6,6 \\
\hline
\end{tabular}

Após a avaliação dos resultados obtidos na incubação dos solos, realizou-se a correção do $\mathrm{pH}$ com $\mathrm{CaCO}_{3}$ e $\mathrm{MgCO}_{3}$, reagentes p.a. na proporção de $3: 1, \mathrm{Ca} / \mathrm{Mg}$ em quantidades equivalentes ao $\mathrm{CaCO}_{3}$ encontrados na curva de calibração. A quantidade de calcário aplicada no solo foi de $6 \mathrm{t}^{\mathrm{h}} \mathrm{ha}^{-1}$, visando elevar o $\mathrm{pH}$ do solo para aproximadamente 6,0 .

\section{Aplicação dos fertilizantes e dos metais pesados tóxicos}

Após a calagem, adicionaram-se os fertilizantes aos vasos. Os fertilizantes aplicados são fontes de micronutrientes, contendo os metais pesados tóxicos, $\mathrm{Cd}, \mathrm{Pb}$ e $\mathrm{Cr}$, que foram previamente determinados. Para os vasos testemunhas não houve adição. Foram utilizados cinco fertilizantes: Stimussed Plus, BR-12 Especial, FTE-Cerrado, Zincogran e Micronutri 121.

O fertilizante Stimussed Plus foi aplicado na semente, na ordem de $0,2 \mathrm{~kg} \cdot \mathrm{ha}^{-1}$ conforme recomendação do fabricante.

Os fertilizantes BR-12 Especial, FTE-Cerrado, Zincogran e Micronutri 121 foram adicionados em dosagens de 50 e 100 $\mathrm{kg} \cdot \mathrm{ha}^{-1}$. Anteriormente, o solo já havia recebido a mesma dosagem para o cultivo de aveia, sem obter sucesso. Por isso, o solo foi novamente preparado e adubado.

Também foram aplicados no solo: sais de cádmio, na forma de cloreto; chumbo, na forma de acetato; e crômio, na forma de cloreto, nas dosagens de 25 e $50 \mathrm{~kg} \cdot \mathrm{ha}^{-1}$ do metal para o tratamento 1 e tratamento 2 respectivamente. Esses sais foram aplicados na forma de solução aquosa antes do plantio.

Os fertilizantes foram peneirados, aproveitando-se apenas a porção que passou pela peneira de malha $1 \mathrm{~mm}$. Isso permitiu que a superfície de contato dos fertilizantes com o solo fosse maior. Desta forma foi obtida uma granulometria mais uniforme. 


\section{Adubação com macronutrientes}

A adubação foi feita através da interpretação da análise química de solo e necessidade da cultura ${ }^{13-14}$, com nitrogênio e fósforo na forma de $\left(\mathrm{NH}_{4}\right)\left(\mathrm{H}_{2} \mathrm{PO}_{4}\right)$ p.a., e potássio na forma de $\mathrm{KCl}$ p.a.. Esses nutrientes foram aplicados como solução aquosa sobre o solo. A adubação de cobertura com sulfato de amônio foi realizada aos vinte e oito dias após a germinação.

\section{Plantio}

Após terem recebido calagem e adubação com macro e micronutrientes, os vasos receberam água destilada e desionizada até atingir a umidade correspondente a $70 \%$ da capacidade de retenção de água, ficando assim por dezoito dias para que os sistemas alcançassem o equilíbrio. Os vasos receberam sementes de aveia. Como não houve germinação devido a problemas com as sementes, o solo foi novamente preparado e adubado. Novamente, adicionou-se água destilada e desionizada até atingir a umidade correspondente a $70 \%$ da capacidade de retenção de água, ficando assim por dezoito dias para que os sistemas alcançassem o equilíbrio. Logo após receberam oito sementes de soja por vaso. Após a germinação das sementes, foi feito um desbaste deixando-se apenas seis plantas por vaso, por um período de quarenta dias.

\section{Coleta do material vegetal}

A coleta da parte aérea das plantas de soja foi realizada quarenta dias após a germinação das plantas com corte rente ao solo. O material vegetal foi acondicionado em sacos de papel para secagem, em estufa a $60^{\circ} \mathrm{C}$ até peso constante, evitandose perdas e contaminação.

A seguir moeram-se as plantas em micro-moinho.

\section{Determinação dos Metais Pesados Tóxicos Cd, $\mathbf{P b}$ e $\mathbf{C r}$ no Material Vegetal}

Para a determinação dos teores de $\mathrm{Cd}, \mathrm{Pb}$ e $\mathrm{Cr}$ nas plantas, digeriram-se $750 \mathrm{mg}$ do tecido vegetal moído, com 7,5 mL de $\mathrm{HNO}_{3}$ concentrado, deixando-se em repouso durante a noite. A digestão foi conduzida a uma temperatura de $160^{\circ} \mathrm{C}$, por aproximadamente 30 minutos até redução da metade do volume de ácido nítrico adicionado. Após esfriamento, acrescentaram-se 2,0 $\mathrm{mL}$ de $\mathrm{HClO}_{4}$ p.a. e a temperatura do sistema digestor foi aumentada para $210^{\circ} \mathrm{C}$, por aproximadamente 20 minutos, até a solução tornar-se límpida. $\mathrm{O}$ produto obtido foi transferido quantitativamente para balão volumétrico de $25 \mathrm{~mL}$ e aferido ${ }^{15}$.

As determinações dos metais pesados nos extratos foram feitas por técnicas de Espectrometria de Absorção Atômica, modalidade chama ${ }^{9-10}$.

\section{Análise Estatística}

Para analisar estatisticamente os resultados obtidos, utilizou-se o Teste Tukey. Este teste é indicado para comparação de médias de tratamentos qualitativos e quantitativos, como: cultivares, tipos de poda e tipos de enxertia ${ }^{16}$.

$\mathrm{Na}$ discussão dos resultados, as médias que apresentam a mesma letra a 1 e $5 \%$ não se diferem estatisticamente. As letras minúsculas e maiúsculas são somente para diferenciar o teste Tukey a 1 e $5 \%$. Em experimentos agroquímicos, a discussão dos resultados obtidos, geralmente, é realizada em cima das médias do teste Tukey a $5 \%$.

\section{RESULTADOS E DISCUSSÃO}

Os resultados obtidos nos testes analíticos realizados no tecido vegetal de soja, dentro das condições em que foi desenvolvido o experimento, permitem fazer as observações que seguem.
O solo LE possui baixa capacidade de troca catiônica (CTC) em relação a solos argilosos, isto pode explicar a disponibilização do cádmio no tecido de soja cultivada neste solo. Em condições de vaso, onde não existem perdas por percolação, o elemento permanece mais na solução do solo, sendo deste modo, no início, mais disponível para as plantas ${ }^{17}$. Sendo assim, em solos com maior CTC, o metal estará menos móvel, em consequência, menos disponíve ${ }^{18}$.

No solo LE, o metal fica mais disponível, podendo, também, em condições de campo, ser lixiviado pelas águas de percolação e, caso não seja absorvido pelas plantas, ser levado aos mananciais de águas ou mesmo ao lençol freático.

Nos resultados obtidos para as testemunhas (Tabela 6), não ocorreu disponibilização de cádmio, mostrando que a aplicação dos adubos contendo o metal deve ser responsável pelo aumento significativo do cádmio no tecido das plantas.

Tabela 6. Média da concentração de cádmio nas plantas testemunhas e análise estatística com teste Tukey a 1 e $5 \%$.

\begin{tabular}{lcccc}
\hline Solo & № Repetições & Médias $\left(\mathrm{mg}^{\mathrm{k}} \mathrm{kg}^{-1}\right)$ & $5 \%$ & $1 \%$ \\
\hline LE & 3 & $0,000^{*}$ & $\mathrm{a}$ & $\mathrm{A}$ \\
\hline
\end{tabular}

* Valor de concentração abaixo do limite de detecção do método.

Considera-se $0,5 \mathrm{mg} \cdot \mathrm{kg}^{-1}$ como valor de referência de cádmio em solos não contaminados. No nosso caso, não foram detectados teores de cádmio no solo trabalhado 5 (Tabela 4).

Em relação aos tratamentos, pelo teste de Tukey a 5\% (Tabela 7), os fertilizantes BR-12 Especial e FTE Cerrado (100 $\left.\mathrm{kg} . \mathrm{ha}^{-1}\right)$ e o tratamento com $\mathrm{CdCl}_{2} \cdot \mathrm{H}_{2} \mathrm{O}\left(50 \mathrm{~kg} \cdot \mathrm{ha}^{-1}\right)$ foram os que mais disponibilizaram cádmio para as plantas diferenciando-se dos demais tratamentos. Estes adubos são os que apresentam maior quantidade deste metal (Tabela 3).

Tabela 7. Médias das concentrações de cádmio na parte aérea das plantas de soja no solo LE e análise estatística com teste Tukey a 1 e $5 \%$.

\begin{tabular}{|c|c|c|c|}
\hline Tratamentos & Média $\left(\mathrm{mg} \cdot \mathrm{kg}^{-1}\right)$ & $5 \%$ & $1 \%$ \\
\hline BR-12 Especial 2 & 0,267 & a & A \\
\hline FTE Cerrado 2出勾 & 0,233 & $\mathrm{a}$ & A \\
\hline $\mathrm{CdCl}_{2} \cdot \mathrm{H}_{2} \mathrm{O} 2 \# \#$ & 0,217 & $\mathrm{a}$ & $\mathrm{AB}$ \\
\hline FTE Cerrado 1卖 & 0,117 & $\mathrm{~b}$ & $\mathrm{BC}$ \\
\hline $\mathrm{CdCl}_{2} \cdot \mathrm{H}_{2} \mathrm{O} \quad 1 \#$ & 0,083 & $\mathrm{bc}$ & $\mathrm{CD}$ \\
\hline BR-12 Especial 1 & 0,067 & $\mathrm{bc}$ & $\mathrm{CD}$ \\
\hline Zincogran 2ts & 0,067 & $\mathrm{bc}$ & $\mathrm{CD}$ \\
\hline Stimussed Plus $\Delta$ & 0,017 & $\mathrm{c}$ & $\mathrm{CD}$ \\
\hline Micronutri 1211 质 & $0,000 *$ & $\mathrm{c}$ & $\mathrm{D}$ \\
\hline Micronutri 1212 光本 & $0,000 *$ & $\mathrm{c}$ & $\mathrm{D}$ \\
\hline Zincogran 1 约 & $0,000 *$ & $\mathrm{c}$ & $\mathrm{D}$ \\
\hline Testemunhas & $0,000^{*}$ & $\mathrm{c}$ & $\mathrm{D}$ \\
\hline
\end{tabular}

$\Delta 0,2 \mathrm{~kg} \cdot \mathrm{ha}^{-1}$; $50 \mathrm{~kg} \cdot \mathrm{ha}^{-1}$; 为 $100 \mathrm{~kg} \cdot \mathrm{ha}^{-1}$; \# $25 \mathrm{~kg} \cdot \mathrm{ha}^{-1}$; \#\# $50 \mathrm{~kg} \cdot \mathrm{ha}^{-1}$

* Valor de concentração abaixo do limite de detecção do método.

Semelhante ao que ocorreu com a disponibilização do cádmio no tecido vegetal, também os resultados encontrados para o chumbo mostraram uma disponibilização significativa no tecido vegetal.

Neste caso, se o chumbo não for absorvido pelas plantas, pode percolar com mais facilidade no perfil do solo LE, podendo talvez, nas condições de campo, atingir o lençol freático.

Para as plantas testemunhas (Tabela 8), não houve disponibilização do metal, mostrando que o aumento da absorção de chumbo pelas plantas se deve à presença dos fertilizantes aplicados. 
Tabela 8. Média da concentração de chumbo nas plantas testemunhas e análise estatística com teste Tukey a 1 e $5 \%$.

\begin{tabular}{lcccc}
\hline Solo & № Repetições & Médias $\left(\mathrm{mg}^{\mathrm{k}} \cdot \mathrm{kg}^{-1}\right)$ & $5 \%$ & $1 \%$ \\
\hline LE & 3 & $0,000^{*}$ & $\mathrm{a}$ & $\mathrm{A}$ \\
\hline
\end{tabular}

* Valor de concentração abaixo do limite de detecção do método.

Com relação aos tratamentos (Tabela 9), o tratamento com o fertilizante BR 12 Especial (100 kg.ha-1) foi o que apresentou plantas com maior concentração de chumbo, sendo que este fertilizante é o que possui a maior concentração do metal (Tabela 3).

Tabela 9. Médias das concentrações de chumbo na parte aérea das plantas de soja no solo LE e análise estatística com teste Tukey a 1 e $5 \%$.

\begin{tabular}{|c|c|c|c|}
\hline Tratamentos Média & $\left(\mathrm{mg} \cdot \mathrm{kg}^{-1}\right)$ & $5 \%$ & $1 \%$ \\
\hline BR-12 Especial 2为 & 5,667 & $\mathrm{a}$ & A \\
\hline FTE Cerrado 2 & 3,833 & $\mathrm{~b}$ & B \\
\hline Micronutri 1212 & 3,667 & bc & $\mathrm{B}$ \\
\hline Zincogran 2 次地 & 2,933 & $\mathrm{~cd}$ & $\mathrm{BC}$ \\
\hline$\left(\mathrm{CH}_{3} \mathrm{COO}\right)_{2} \mathrm{~Pb}_{3} \mathrm{H}_{2} \mathrm{O}$ 2\#\# & 2,300 & de & $\mathrm{CD}$ \\
\hline BR-12 Especial $1 \triangleleft$ & 2,033 & ef & $\mathrm{CDE}$ \\
\hline FTE Cerrado 1 次 & 1,700 & efg & $\mathrm{DE}$ \\
\hline$\left(\mathrm{CH}_{3} \mathrm{COO}\right)_{2} \mathrm{~Pb}_{3} \mathrm{H}_{2} \mathrm{O} \quad 1 \#$ & 1,600 & efg & $\mathrm{DE}$ \\
\hline Zincogran 1 次 & 1,300 & fg & $\mathrm{E}$ \\
\hline Micronutri 121 颈 & 1,133 & $\mathrm{~g}$ & $\mathrm{E}$ \\
\hline Stimussed Plus $\Delta$ & 1,133 & $\mathrm{~g}$ & $\mathrm{H}$ \\
\hline Testemunhas & $0,000 *$ & $\mathrm{~h}$ & $\mathrm{~F}$ \\
\hline
\end{tabular}

$\Delta 0,2 \mathrm{~kg} \cdot \mathrm{ha}^{-1}$; $50 \mathrm{~kg} \cdot \mathrm{ha}^{-1}$; 必 $100 \mathrm{~kg} \cdot \mathrm{ha}^{-1}$; \# $25 \mathrm{~kg} \cdot \mathrm{ha}^{-1}$; \#\# $50 \mathrm{~kg} \cdot \mathrm{ha}^{-1}$

* Valor de concentração abaixo do limite de detecção do método.

A testemunha ficou isolada pelo teste de Tukey a $5 \%$ e o tratamento com o fertilizante Stimussed Plus ficou logo a seguir acompanhado pelo tratamento com o fertilizante Micronutri 121 (50 kg.ha $\left.{ }^{-1}\right)$. Também, entre os tratamentos que menos disponibilizaram o metal, estão FTE Cerrado (50 $\left.\mathrm{kg} \cdot \mathrm{ha}^{-1}\right),\left(\mathrm{CH}_{3} \mathrm{COO}\right)_{2} \mathrm{~Pb} 3 \mathrm{H}_{2} \mathrm{O}\left(25 \mathrm{~kg} \cdot \mathrm{ha}^{-1}\right)$ e Zincogran (50 kg.ha ${ }^{-1}$ ), (Tabela 9).

No solo LE, de característica arenosa, o chumbo estará na solução de solo, desta forma mais disponível para as plantas.

Já em solos com altos teores de matéria orgânica e alto conteúdo de argila, ocorrerá um maior efeito de adsorção de chumbo, sendo assim os metais estão menos disponíveis para as plantas, o que explica a capacidade de adsorção e menor disponibilidade dos metais nesses solos ${ }^{19}$.

Semelhante ao que ocorreu com o cádmio e o chumbo, os resultados obtidos na determinação de crômio no tecido vegetal de soja revelaram que em todos os tratamentos houve disponibilização do metal.

$\mathrm{Na}$ Tabela 10, observa-se que, diferente do que ocorreu com o cádmio e o chumbo, as plantas testemunhas apresentaram diferença significativa de crômio, mostrando que para este elemento, o próprio solo contribuiu para a liberação do metal para as plantas, o que pode ser explicado pela maior concentração do elemento no solo (Tabela 4), em relação ao cádmio e o chumbo.

Tabela 10. Média da concentração de crômio nas plantas testemunhas e análise estatística com teste Tukey a 1 e $5 \%$.

\begin{tabular}{lcccc}
\hline Solo & № Repetições & Médias $\left(\mathrm{mg}^{\mathrm{k}} \mathrm{kg}^{-1}\right)$ & $5 \%$ & $1 \%$ \\
\hline $\mathrm{LE}$ & 3 & 1,93 & $\mathrm{a}$ & $\mathrm{A}$ \\
\hline
\end{tabular}

Para os tratamentos aplicados neste solo (Tabela 11), a disponibilização de crômio que ocorreu no tratamento com $\mathrm{CrCl}_{3} 6 \mathrm{H}_{2} \mathrm{O}$ $\left(50 \mathrm{~kg} \mathrm{ha}^{-1}\right)$, destaca-se pela maior disponibilização, mas pelo teste de Tukey a $5 \%$, não se diferencia dos tratamentos com os fertilizantes Zincogran (100 kg.ha-1) e BR-12 Especial (100 kg.ha' $\left.{ }^{-1}\right)$.

Tabela 11. Médias das concentrações de crômio na parte aérea das plantas de soja no solo LE e análise estatística com teste Tukey a 1 e $5 \%$.

\begin{tabular}{|c|c|c|c|}
\hline Tratamentos & Média $\left(\mathrm{mg} \cdot \mathrm{kg}^{-1}\right)$ & $5 \%$ & $1 \%$ \\
\hline $\mathrm{CrCl}_{3} 6 \mathrm{H}_{2} \mathrm{O} 2 \# \#$ & 4,500 & a & A \\
\hline Zincogran 2地 & 4,333 & $a b$ & A \\
\hline BR-12 Especial 2 & 4,250 & $a b$ & A \\
\hline Stimussed Plus $\Delta$ & 3,683 & $\mathrm{bc}$ & $\mathrm{AB}$ \\
\hline Micronutri 1212 幽次 & 3,250 & $\mathrm{~cd}$ & $\mathrm{BC}$ \\
\hline Zincogran 1 级 & 3,167 & $\mathrm{~cd}$ & $\mathrm{BC}$ \\
\hline BR-12 Especial 1㑔 & 3,167 & $\mathrm{~cd}$ & $\mathrm{BC}$ \\
\hline $\mathrm{CrCl}_{3} 6 \mathrm{H}_{2} \mathrm{O} \quad 1 \#$ & 3,083 & $\mathrm{~cd}$ & $\mathrm{BC}$ \\
\hline FTE Cerrado 2九次 & 3,083 & $\mathrm{~cd}$ & $\mathrm{BC}$ \\
\hline Micronutri 1211 不 & 2,750 & $\mathrm{~d}$ & $\mathrm{BCD}$ \\
\hline FTE Cerrado 1 次 & 2,667 & de & $\mathrm{CD}$ \\
\hline Testemunhas & 1,933 & $\mathrm{e}$ & $\mathrm{D}$ \\
\hline
\end{tabular}

Pelo teste de Tukey a 5\%, os tratamentos que menos disponibilizaram crômio para as plantas cultivadas neste solo foram: a testemunha e o fertilizante FTE Cerrado $\left(50 \mathrm{~kg} \cdot \mathrm{ha}^{-1}\right)$.

As diferentes características de cada solo, influenciam de forma direta na disponibilização destes metais no tecido vegetal de soja, sendo que o solo LE possuí uma grande capacidade de liberar estes elementos no sistema solo-planta.

\section{CONCLUSÃO}

A aplicação de fertilizantes com micronutrientes mostrou uma efetiva disponibilização de $\mathrm{Cd}, \mathrm{Pb}$ e $\mathrm{Cr}$ para as plantas de soja.

Em relação ao cádmio, os fertilizantes que mais disponibilizaram o metal para as plantas foram o BR 12 Especial 2, FTE Cerrado 2 e o tratamento com $\mathrm{CdCl}_{2} \cdot \mathrm{H}_{2} \mathrm{O}$. As menores concentrações de cádmio no tecido de soja foram detectadas nos tratamentos com os fertilizantes Micronutri 121 e Zincogran.

Em relação ao chumbo, a maior liberação do metal para as plantas de soja ocorreu com o fertilizante BR 12 Especial 2. Nesse solo, o fertilizante que menos disponibilizou chumbo foi o Stimussed Plus.

Para o crômio, o tratamento com $\mathrm{CrCl}_{3} 6 \mathrm{H}_{2} \mathrm{O} 2$ foi o que mais disponibilizou o metal para as plantas. Os fertilizantes Zincogran 2, BR-12 Especial 2, Stimussed Plus e Micronutri 1212 também se destacaram na liberação do metal para as plantas. A menor liberação de crômio para as plantas, foi do fertilizante FTE Cerrado 1.

$\mathrm{O}$ aumento da dosagem das aplicações dos fertilizantes e dos sais contendo os metais pesados tóxicos aumentou a concentração dos metais nas plantas, em todos os casos.

\section{AGRADECIMENTOS}

Agradecemos à Capes pelo auxílio financeiro e aos Professores Dr. Valfredo Tadeu de Fávere e Dr. Mauro C. M. Laranjeira (QUITECH - UFSC), pelas sugestões.

\section{REFERÊNCIAS}

1. Gonçalves Jr., A. C.; Dissertação de Mestrado; Universidade Estadual de Maringá, Maringá-PR, 1998. 
2. Barceló, J.; Poschenrieder, C.; Suelo y Planta 1992 , 2, 345 .

3. Malavolta, E.; Fetilizantes e seu Impacto Ambiental: metais pesados, mitos, mistificação e fatos; Produquímica; São Paulo, 1994

4. Alloway, B. J.; Heavy Metals in Soils; New York, 1990

5. Kabata-Pendias, A.; Pendias, H.; Trace Elements in Soils and Plants; CRC PRESS; Boca Raton, 1984

6. Amaral Sobrinho, N. M. B.; Costa L. M.; Oliveira C.; Velloso, A. C. X.; R. Bras. Ci. Solo. 1992, 16, 271.

7. Lanziani, A.; Dissertação de Mestrado; Universidade Estadual de Maringá, Maringá-PR, 1995.

8. Beckett, P. H. T.; Critical tissue concentrations as indicators of toxicity; Suelos Ecuatoriales, Bogotá, 1991, p 39.

9. Welz, B.; Atomic Absorption Spectrometry; VCH; Weinheim, 1985, p 253.

10. Lajunem, L. H. J.; Spectrochemical Analysis by Atomic Absorption and Emission; Royal Society of Chemistry, Cambridge, 1992, p 153.
11. Pavan, M. A.; Miyazawa, M.; Análises Químicas de Solo: Parâmetros para Interpretação; (Circular Técnica, 91); IAPAR; Londrina, 1996

12. Luchese, E. B.; Tese de Doutorado; ESALQ - USP; Piracicaba-SP, 1992.

13. Organização das Cooperativas do Estado do Paraná; Recomendações Técnicas para a Cultura de Soja no Paraná 1994/95; (Boletim Técnico, 36); OCEPAR/EMBRAPACNPSo; Cascavel, 1994

14. Derpesch, R; Calegari, A.; Plantas para Adubação Verde de Inverno; (Circular Técnica, 73); IAPAR; Londrina, 1992, p 41.

15. Sarruge, J. R.; Haag, H. P.; Análise Química em Plantas; Livroceres, Piracicaba, 1974

16. Pimentel Gomes, F.; Estatística Moderna na Pesquisa Agropecuária; Potafos, Piracicaba, 1984, p 126.

17. Miller, J. E.; J. Environ. Qual. 1976, 5, 157.

18. John, M. K; Can. J. Soil Sci. 1972, 52, 343.

19. Hassett, J. J.; Commun. Soil Sci. Plant Anal. 1974, 5, 499. 